The reason remains unknown. In view of its unusual appearance it is very unlikely that the pathology is ever missed at bronchoscopy or autopsy.

\section{Acknowledgments}

I am grateful to Mr W. F. Nicholson, M.B.E., M.D., M.Ch., F.R.C.s., for helpful suggestions. I wish to thank Dr J. B. Mitchell and Mr Nicholson for the permission to publish these cases. Dr Ollerenshaw of the medical illustration department and Mr R. Neave, the University medical artist, deserve special thanks.

\section{References}

Aschoff, L. (1910) Uber Tracheopathia Osteoplastica. Verh. dtsch. path. Ges. 14, 125.

BAIRD, R.B. \& MACARTNEY, J.N. (1966) Tracheopathia osteoplastica. Thorax, 21, 321.

Bowen, D.A.L. (1959) Tracheopathia osteoplastica. J. clin. Path. 12, 435.

CARR, D.T. \& Osler, A.M. (1954) Tracheopathia osteoplastica. J. Amer. med. Ass. 155, 1563.
DAlgaARD, J.B. (1947) Tracheopathia chondro-osetoplastica. Acta path. microbiol. scand. 24, 118.

DAlgAARD, J.B. (1955) Lungecancer Ved. tracheopathia chrondro-osteoplastica. Nord. Med. 53, 572.

Gilbert, J.G., Mazzorella, L.A. \& Feit, L.J. (1953) Primary tracheal tumours in the infant and adult. Arch. Otolaryng. 58, 1.

HAMPel, K.J. \& GläseR, A. (1958) Zur Pathogenese der Tracheopathia chondro-osteoplastica. Virchows Arch. path. Anat. 331, 36.

Hiebaum, K. (1934) Uber knochenbildungen in Lunge und Trachea. Frankfurt. Z. Path. 47, 249.

Huzley, A. (1960) An Atlas of Bronchoscopy. Grune \& Stratton, New York.

LELL, W.A. (1953) Tracheopathia osteoplastica, report of a case. Dis. Chest, 23, 568.

SeCrest, P.G., Kendig, T.A. \& Belord, A.J. (1964) Tracheobronchopathia osteochondroplastica. Amer. J. Med. 36, 815.

SPENCER, H. (1962) Pathology of the Lung, p. 591. Pergamon Press, Oxford.

ViRchow, R. (1863) Die Krankhaften Geschwulste, vol. 1, p. 443. Hirschwald, Berlin.

WiLks, S. (1857) Ossific deposits on the larynx, trachea and bronchi. Trans. path. Soc. Lond. 8, 88.

\title{
Duodenal obstruction due to an anomalous portal vein
}

\author{
V. V. KAKKAR* \\ F.R.C.S.E., F.R.C.S.
}
A. M. B. TOMPKIN
F.R.C.S.

Gravesend and North Kent Hospital, Gravesend

CONGENITAL malformations of the portal venous system are rare. Of these, the pre-duodenal position of the portal vein is of special surgical significance because of its dangerous situation in operations involving the duodenum and biliary tract, the difficulty it causes in radiological interpretation and because it can be responsible for duodenal obstruction.

We recently encountered a patient in whom duodenal obstruction from this cause produced interesting gastric symptoms.

\section{Case report}

Mr M.B., aged 29 years, was admitted to hospital complaining that he had to take two meals in quick succession. He would feel hungry within half an hour of taking the first meal and require another meal. He also complained of occasional attacks of epigastric pain following immediately after the second meal and relieved by vomiting. He had had one haematemesis 3 years previously after the ingestion of a large quantity of alcohol. There was no history of melaena or weight loss.

\footnotetext{
* Present address: Department of Surgery, King's College Hospital Medical School, London.
}

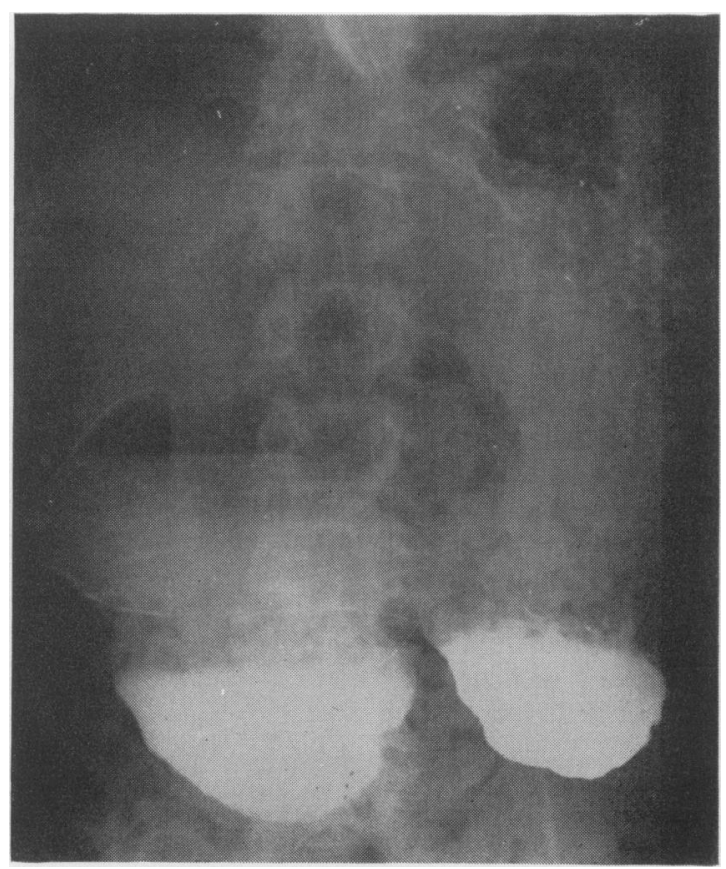

Fig. 1. Showing obstruction in the first part of duodenum and 'double bubble' appearance. 


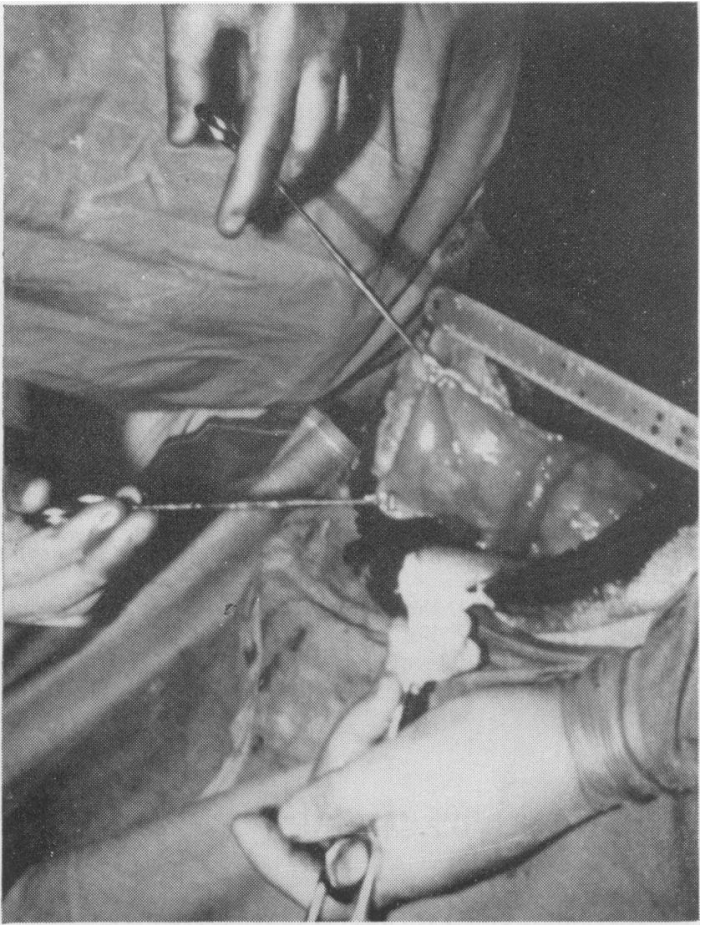

FIG. 2. Anterior transposition of the portal vein passing in front of first and second part of duodenum and causing obstruction.

On examination no physical signs were detected in the abdomen and in particular no succussion splash was present. Plain X-ray of the abdomen showed a characteristic 'double bubble' sign of duodenal obstruction. Barium meal showed an obstruction in the first part of the duodenum and the pylorus was difficult to localize (Fig. 1).

At operation there was no evidence of pyloric obstruction, but the first part of the duodenum was markedly dilated. The obstructing agent was an anomalous portal vein passing in front of the first and second parts of the duodenum and compressing it (Fig. 2); the course continued in front of the common bile duct and hepatic artery. There was no evidence of malrotation of gut.

A retro-colic gastrojejunostomy was performed and the post-operative period was uneventful. When last seen he had been completely symptomfree since his operation.

\section{Discussion}

Only nine cases of an anomalous portal vein causing duodenal obstruction have been previously recorded (Stengel, 1934; Snaveley \& Breaknell, 1954 ; Bernard, Perry \& Walker, 1959 ;
Boles \& Smith, 1961 ; Block \& Zikoia, 1961). This anterior transposition of the portal vein can be explained on an embryological basis. In the embryo, the venous blood from the primitive gut is drained by the two parallel vitelline veins of the yolk sac (Knight, 1921; Avey, 1954). Later three anastomotic channels (cephalad, middle and caudal) connect the two vitelline veins. The cephalad anastomosis lies within the liver, the middle anastomosis is dorsal or posterior to the duodenum and the caudal anastomosis is situated ventral or anterior to the duodenum. Normally parts of this venous system atrophy and the remaining segments form the normal portal vein. The caudal portion of the right vitelline vein and the cephalad segment of the left vitelline vein disappear, leaving an S-shaped portal vein which passes behind the duodenum. If instead the caudal anastomosis and a portion of the right vitelline vein remain, then the preduodenal portal vein results. This anomaly is not uncommonly associated with situs inversus, biliary atresia or dextrocardia (Duaglass, Baggentossa-Hollinstead, 1950 ; Gilfillam, 1950). In the present patient, all the viscera were in their normal anatomic positions.

The obstruction caused by a preduodenal portal vein can be relieved by gastrojejunostomy or duodenoduodenostomy, the latter being the procedure of choice in infants and young children. Obstruction can best be relieved in adults by gastrojejunostomy with or without subdiaphragmatic vagotomy.

\section{References}

Avey, L.B. (1954) Developmental Anatomy, 6th edn, p. 377. Saunders, Philadelphia.

Bernard, L.I., Perry, F.A. \& Walker, M. (1959) Preduodenal portal vein causing duodenal obstruction with bleeding duodenal ulcer. Ann. Surg. 150, 909.

Block, M.A. \& ZikrIA, E.A. (1961) Pre-duodenal portal vein causing duodenal obstruction associated with pueumatosis cystoides intestinalis. Ann. Surg. 153, 407.

Boles, E.T., JR \& Smith, B. (1961) Pre-duodenal portal vein. Pediatrics, 28, 805.

Duaglass, B.E., Baggenstoss, A.N. \& Hollinstead, W.H. (1950) Variations in the portal systems of veins. Proc. Mayo Clin. 25, 26.

GilfillaM, R.S. (1950) Anatomic study of portal vein and its main branches. Arch. Surg. 61, 58.

KNIGHT, S.O. (1921) An anomalous portal vein with its surgical dangers. Ann. Surg. 74, 697.

SNAVELY, J.G. \& BREAKNell, E.S. (1954) Fatal haemorrhage from esophageal varices due to malformation and congenital stenosis in the portal venous system. Amer.J. Med. 16, 459 .

Stengel, F. (1934) Über zwei Fälle von Praduodenalem verlauf der Pfortader lui normaler lage von magen und Duodenum. Z. Anat. Entwickl.-gesch. 102, 661. 